\title{
Preparation of MIL-53(Fe)/BiOCl composites and its photo-Fenton performance in degradation of 2,4-DCP under visible light
}

\author{
Yaru Zhang ${ }^{1, a}$, Kegang Zhang ${ }^{1, b}$, Xiaodong Wang ${ }^{1, c, *}$ and Tao Yan $^{2, d}$ \\ ${ }^{1}$ School of Civil Engineering and Architecture, University of Jinan, Jinan 250022, PR China \\ ${ }^{2}$ School of Water conservancy and Environment, University of Jinan, Jinan 250022, PR China

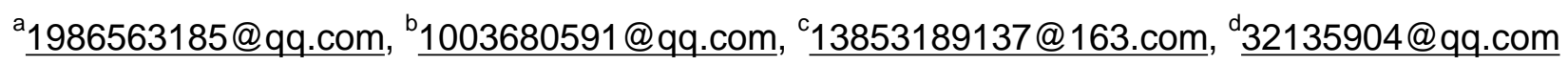

Keywords: MIL-53(Fe)/BiOCl; solvothermal synthesis; photo-Fenton effect; 2,4-DCP;

Abstract. The MIL-53(Fe)/BiOCl composite catalyst is triumphantly man-made by two-step solvothermal method. The MIL-53(Fe) which possesses nanoscale polyhedral structure is loaded to the surface of $\mathrm{BiOCl}$ microspheres. 2,4-DCP is regarded as a simulated pollutant in environmental wastewater, at the same time, $\mathrm{H}_{2} \mathrm{O}_{2}$ is added into the reaction vessel. The photo-Fenton performance of the composites has been tested. Making use of photo-Fenton effect of $\mathrm{H}_{2} \mathrm{O}_{2}$ and iron ions under visible light, photo-Fenton effect is used to investigate the photocatalytic degradation efficiency of higher concentration of 2,4-DCP under different conditions. And the photochemical properties of XRD, DRS and SEM as well as the electrochemical properties of PL, PC and EIS are measured. The catalytic mechanism is analyzed by photo-Fenton effect.

\section{Introduction}

In the last few years, the semiconductor photocatalysis research is becoming a hot topic which has been applied in wastewater treatment ${ }^{[1-4]}$. It is used in the photocatalytic degradation on organic pollutant in the wastewater and air handle. $\mathrm{TiO}_{2}$ is acted as a representative photocatalytic material which possesses the low utilization efficiency for solar energy. At the same time, its optical absorption range is very narrow. So it is only used in photocatalytic degradation in ultraviolet region ${ }^{[5-8]}$. Besides, $\mathrm{TiO}_{2}$ have a lower quantum efficiency by reason of the rapid recombination between electron-hole pairs ${ }^{[9]}$. So exploiting the new type photocatalytic materials, broadening its optical absorption scope and improving the separation efficiency of electron-hole pairs have been becoming a noticeable spot ${ }^{[10]}$.

MOFs materials are composed of metal ions and organic linkers. It is a new-style material having tunable structure properties and functionalities. MOFs exhibit the potential application of gas storage, catalysis and drug delivery ${ }^{[11-14]}$. MIL-53(Fe) is a new photocatalytic crystalline material, transition metal is acted a bridge connected by organic linkers, its application in photocatalytic filed has been widely concerned ${ }^{[15]}$.MIL-53(Fe) is a three-dimentional porous organic framework. It provides a good carrier for other semiconductors. In particular, organic linker can absorb photon, resulting in the migration from metal to organic linker and making MIL-53(Fe) become an adjustable multifarious metal organic framework ${ }^{[16]}$. Researchers ${ }^{[17]}$ reported g- $\mathrm{C}_{3} \mathrm{~N}_{4} / \mathrm{MIL}-53(\mathrm{Fe})$ composite material has displayed the photocatalytic performance on the degradation of $\mathrm{Cr}^{6+}$. Some researchers ${ }^{[18]}$ showed a novel CdS/MIL-53(Fe) photocatalyst displayed an outstanding photocatalytic activity on $\mathrm{RhB}$ in water treatment. In the last few years, bismuth semiconductor applied in photocatalytic degradation had caused many attentions among researchers. In these materials, $\mathrm{BiOCl}$ is regarded as the more vibrant photocatalytic material than titanium dioxide due to its layered structure and higher stability ${ }^{[19]}$. Hower, $\mathrm{BiOCl}$ is still facing a challenge because of narrow light absorption range. Many researchers have made great efforts to make BiOCl-based visible-light composites by loading metal or matching with other semiconductor materials ${ }^{[20]}$. Now we have synthesised a novel MIL-53(Fe)/BiOCl material that exhibited superior photo-Fenton performance under the visible-light irradiation. MIL-53(Fe)/BiOCl-10 composites with adding the MIL-53(Fe) have been successfully man-made via two-step solvothermal method. The composite materials could take advantage of photo-Fenton to degrade the 2,4-dichlorophenol ${ }^{[21]}$. 
The photo-Fenton activity of composite material has been assessed by degradation performance of 2,4-dichlorophenol.

\section{Experimental}

\section{Materials}

Solvents and reagents are purchased from mercantile suppliers without any purification. Iron(III) chloride hexahydrate $\left(\mathrm{FeCl}_{3} \cdot 6 \mathrm{H}_{2} \mathrm{O}\right)$, terephthalic acid $\left(\mathrm{H}_{2} \mathrm{BDC}\right), \mathrm{N}$, N-dimethylformamide (DMF), $\mathrm{H}_{2} \mathrm{O}_{2}(30 \%)$, ethanol (EtOH), ethylene glycol (EG), bismuth pentahydrate $\left(\mathrm{Bi}\left(\mathrm{NO}_{3}\right)_{3} \cdot 5 \mathrm{H}_{2} \mathrm{O}\right)$, potassium chloride $(\mathrm{KCl}), \mathrm{HCl}$ and $\mathrm{NaOH}$ are purchased from Shanghai Chemical Plant or Tianjin Chemical Plant. Deionized water (DI) is also used in all experiments.

\section{Preparation of materials}

\section{Synthesis of MIL-53(Fe)}

MIL-53(Fe) is man-made by a facile method according to the previous literature ${ }^{[22]}$. In a representative procedure, $0.674 \mathrm{~g} \mathrm{FeCl}_{3} \cdot 6 \mathrm{H}_{2} \mathrm{O}$ and $0.415 \mathrm{~g} \mathrm{H}_{2} \mathrm{BDC}$ are dissolved in $56 \mathrm{~mL}$ DMF. Then it is mixed and stirred until it becomes a clear solution. The mixture is transferred into a Teflon liner which has the $100 \mathrm{~mL}$ capacity and heated at $170^{\circ} \mathrm{C}$ for $24 \mathrm{~h}$. After cooled down to indoor temperature naturally, the products are filtered, rinsed with $\mathrm{DMF}$ and $\mathrm{C}_{2} \mathrm{H}_{5} \mathrm{OH}$ several times, respectively. The yellow powder is collected and dried at $100^{\circ} \mathrm{C}$ for $10 \mathrm{~h}$.

\section{Synthesis of MIL-53(Fe)/BiOCl-10 and BiOCl}

We have manufactured the MIL-53(Fe)/BiOCl materials using a simple solvothermal method. In a representative technology, the calculated amount of MIL-53(Fe) powders are dissolved in 40 $\mathrm{mL}$ ethylene glycol solvent and suspended with the aid of ultrasonication until it becomes a homogeneous solution. Then $2.6044 \mathrm{~g} \mathrm{Bi}\left(\mathrm{NO}_{3}\right)_{3} \cdot 5 \mathrm{H}_{2} \mathrm{O}$ is added into the above solution under magnetic stirring until it is dissolved completely. A $40 \mathrm{~mL}$ ethylene glycol solution containing $0.7456 \mathrm{~g} \mathrm{KCl}$ is added by drowise into the forming mixture. And the resulting mixture is stirred for $1 \mathrm{~h}$. Finally, it is transferred into a $100 \mathrm{~mL}$ Teflon liner and heated at $160^{\circ} \mathrm{C}$ for $12 \mathrm{~h}$. The product is filterd, rinsed with $\mathrm{C}_{2} \mathrm{H}_{5} \mathrm{OH}$ once time, distilled water three times and dried at $60^{\circ} \mathrm{C}$ overnight. The product is named as $\mathrm{MIL}-53(\mathrm{Fe}) / \mathrm{BiOCl}-10$. The pure $\mathrm{BiOCl}$ is man-made under the similar procedure in the short of MIL-53(Fe) ${ }^{[23]}$.

\section{Characterization techniques}

X-ray diffraction (XRD) patterns of products are carried out using D8 Advance purchased by German Bruker Co. using $\mathrm{Cu}$ Ka radiation at $40 \mathrm{kV}$ and $40 \mathrm{~mA}$ in the $2 \theta$ range of $5-80^{\circ}$ with a scan speed of $4 \% \mathrm{~min}$. The morphology characteristic and structure of the products are observed by scanning electron microscope( Nano SEM 230) purchased from American FEI. The UV-vis diffuse reflectance spectra (DRS) of products are carried out in the scope of 200-700 nm with Varian Cary 500UV-vis spectrophotometer purchased from Ameican Varian Company and $\mathrm{BaSO}_{4}$ is employed as the blank standard. The photoluminescence (PL) spectra of samples are tested with Hitachi 4500.

\section{Photocatalytic evaluation}

The photo-Fenton performance of catalysts are assessed by the degradation curve of 2 , 4-dichlorophenol with the aid of $\mathrm{H}_{2} \mathrm{O}_{2}(30 \%)$. The degradation tests are carried out in a reactor which has a water circulation installation. A 300W Xe arc lamp with 420nm cutoff filter is applied to form the reaction system. In order to accomplish adsorption-desorption balance, $0.05 \mathrm{~g}$ samples are added into $50 \mathrm{~mL} 20 \mathrm{mg} / \mathrm{L} \mathrm{2,4-dichlorophenol} \mathrm{keeping} \mathrm{under} \mathrm{dark} \mathrm{for} 4 \mathrm{~h}$ before irradiation. Then $\mathrm{H}_{2} \mathrm{O}_{2}(30 \%)$ is also added into the system. After irradiation, the suspension samples of $3 \mathrm{~mL}$ are taken out, centrifuged and analyzed immediately. The absorbance at $284 \mathrm{~nm}$ of pollutant is measured by a UV-vis spectrometer (lambda35, USA) to obtain the concentration of 2, 4-DCP. The photocatalytic performance is shown by $\mathrm{C} / \mathrm{C}_{0}$, where $\mathrm{C}_{0}$ is original 2,4-dichlorophenol and $\mathrm{C}$ is remaining concentration of it at the time.

\section{Electrochemical tests}

The electrochemical impedance spectroscopy (EIS) and the photocurrent (PC) are tested on the 
CHI 760E electrochemical workstation purchased from Chenhua Instrument Company. The sample lies in a traditional three-electrode. Photocurrent (PC) is tested by a $300 \mathrm{~W} \mathrm{Xe} \operatorname{arc~lamp~}(\lambda>420 \mathrm{~nm})$ in $0.1 \mathrm{M}$ PBS aqueous solution. The EIS has been measured under the dark condition in the mixture solution $(2.5 \mathrm{mmol} / \mathrm{L}$ potassium ferricyanide, $2.5 \mathrm{mmol} / \mathrm{L}$ potassium hexacyanoferrate and $0.1 \mathrm{~mol} / \mathrm{L}$ editpotassium cyanide).

\section{Results and discussion}

\section{Characterization}

Fig.1 shows the typical XRD patterns of the BiOCl, MIL-53(Fe) and MIL-53(Fe)/BiOCl composites that have been prepared. Obviously, the clear diffraction peaks have implied the well-crystallization property of the MIL-53(Fe). And it has the good consistency with the relevant references ${ }^{[22,24]}$. More importantly, the MIL-53(Fe)/BiOCl-10 displays the alike XRD patterns as that of the BiOCl. It is indicated that the addition of MIL-53(Fe) has slight impact on the structure of $\mathrm{BiOCl}{ }^{[25]}$. It could put down to the low content and high dispersion of it in the MIL-53(Fe)/BiOCl ${ }^{[26]}$. While for pure $\mathrm{BiOCl}$, these remarkable diffraction peaks can match with the literature $^{[23]}$. The XRD result indicates the structure of pure $\mathrm{BiOCl}$ sample is intact. The results of XRD analysis prove clearly the compsite material is consisted of MIL-53(Fe) and BiOCl.

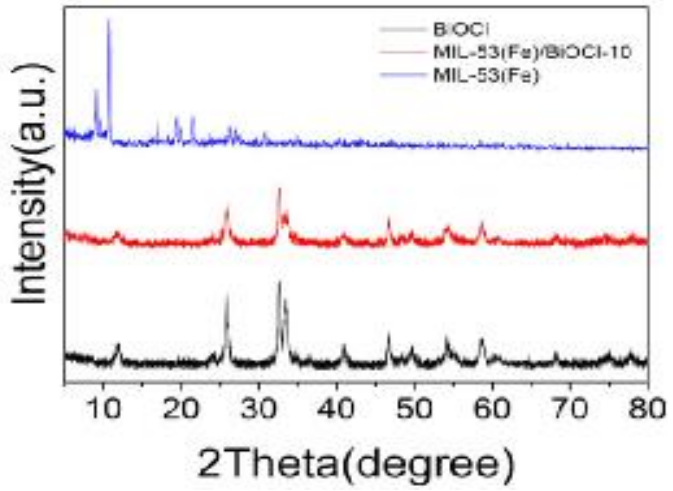

Fig.1 XRD patterns of BiOCl, MIL-53(Fe) and MIL-53(Fe)/BiOCl-10.

Fig.2 shows the SEM images of the BiOCl, MIL-53(Fe)/BiOCl-10 and MIL-53(Fe) samples. As is described in Fig.2(a), the alone MIL-53(Fe) shows the well-defined polyhedrone shape whose diameter is approximately $200 \mathrm{~nm}$ and length is roughly $500 \mathrm{~nm}$. As is seen in Fig.2(b), it can be inferred that the polyhedron structure of the MIL-53(Fe) is covered closely on the surface of BiOCl micrometer structure. However, MIL-53(Fe) is dispersed inhomogeneously on the surface of BiOCl because the part of MIL-53(Fe) is wrapped by $\mathrm{BiOCl}$ micrometer structure. Fig.2(c) shows the pure $\mathrm{BiOCl}$ is composed of flower-structure microballoon with 1-2um. It is coincident with the relevant literature ${ }^{[23]}$.
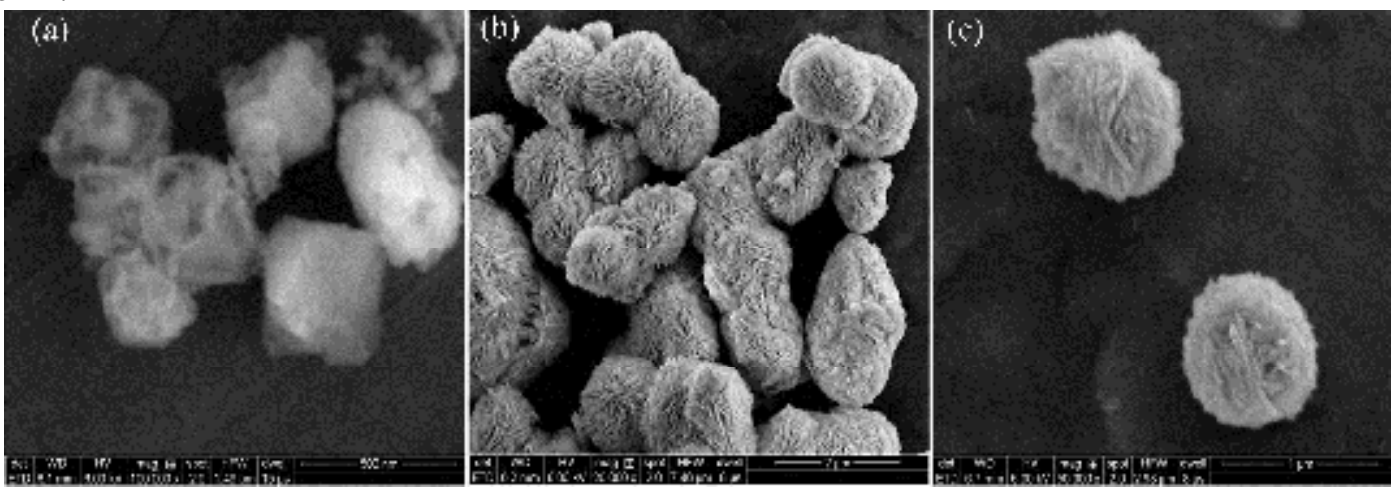

Fig.2 SEM images of MIL-53(Fe) (a), MIL-53(Fe)/BiOCl-10(b) and $\mathrm{BiOCl}(\mathrm{c})$

The optical performance of MIL-53(Fe)/BiOCl composite materials have been tested using UV-vis diffuse reflectance spectra. As is exhibited in Fig.3(a), all samples show stronger absorption within the range of 200-460 $\mathrm{nm}$. The absorption edge positions of MIL-53(Fe) in the ultraviolet 
district are due to transitions of ligands. While, the absorption edge under visible light belongs to the LMCT phenomenon from $\mathrm{H}_{2} \mathrm{BDC}$ ligands to $\mathrm{Fe}^{3+}$ centers ${ }^{[27,28]}$. After MIL-53( $\left.\mathrm{Fe}\right)$ is embedded into $\mathrm{BiOCl}$, the absorption edge of the composites can be red shift by improving the mass of MIL-53(Fe). Obviously, the tangent line of absorption boundary of MIL-53(Fe) is roughly situated at $456 \mathrm{~nm}$, according to the formula of $\mathrm{Eg}=1240 / \lambda^{[29]}$. It can be calculated to a $2.72 \mathrm{eV}$ of band gap. The band gap of $\mathrm{BiOCl}$ is $3.14 \mathrm{eV}$. The Fig.3(a) indicates the MIL-53(Fe)/BiOCl-10 shows higher absorption range than single $\mathrm{BiOCl}$, it is implied that composite material is a promising photocatalyst in the visible light. The PL demonstrates the lower recombination efficiency of the $\mathrm{e}^{-}-$ $\mathrm{h}^{+}$pairs of MIL-53(Fe)/BiOCl-10. As is displayed in Fig.3(b) , a wide band at 300-575 nm with a peak at $280 \mathrm{~nm}$ is aroused. The alike peaks are exisited in the MIL-53(Fe)/BiOCl composites. It could also be observed that the PL intensity of the composites follows the sequence: MIL-53(Fe) > $\mathrm{BiOCl}>\mathrm{MIL}-53(\mathrm{Fe}) / \mathrm{BiOCl}-10$. It is indicated that the composite material has the lower recombination efficiency. It is proved that the close touch between the MIL-53(Fe) and the BiOCl has reduced the recombination efficiency of the electron-hole. The lower recombination efficiency of the composite material would make it more efficient for photo-Fenton applications.
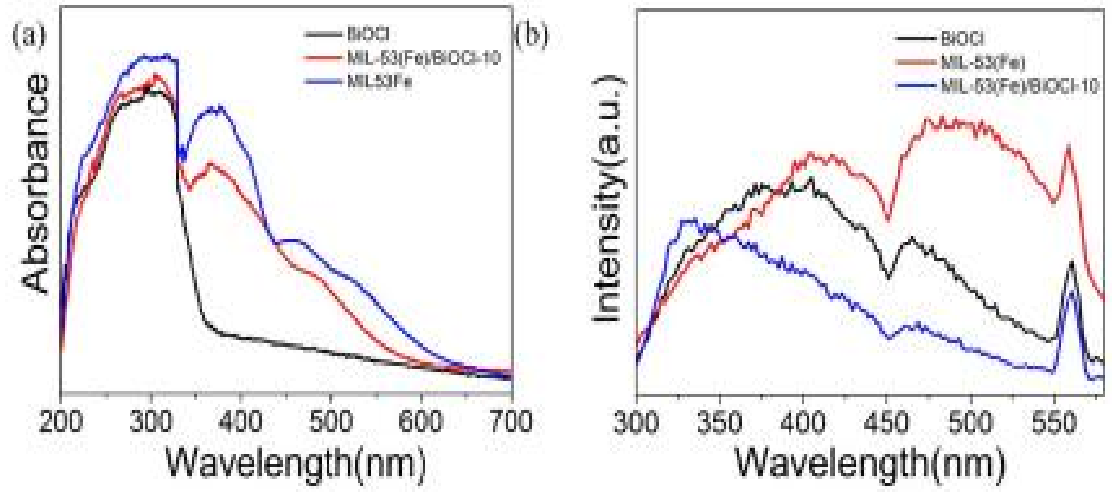

Fig.3 (a) UV-vis diffuse reflectance spectra (UV-vis DRS) and (b) photoluminescence spectra (PL) of the samples.

Photocatalytic performance of 2,4-DCP under $\mathrm{H}_{2} \mathrm{O}_{2}$-MIL-53(Fe)/BiOCl-10 system

Fig.4(a) shows the evolution process of pollutant over time after $10 \mathrm{uL} \mathrm{H}_{2} \mathrm{O}_{2}$ is added. After 150 min, the concentration of 2,4-DCP in the short of the catalyst is no obvious change reflecting that the 2,4-DCP is very steady. However, the existence of $\mathrm{H}_{2} \mathrm{O}_{2}$ could improve the degradation efficiency of 2,4-DCP reaching up to $10 \%$ by photo-Fenton degradation. The possible photo-Fenton activity is lured by visible light (visible light $\left.+\mathrm{H}_{2} \mathrm{O}_{2} \rightarrow \cdot \mathrm{OH}+\mathrm{OH}^{-}\right)^{[30]}$. In the meanwhile, the degradation efficiency of 2,4-DCP by MIL-53(Fe)/BiOCl-10 without $\mathrm{H}_{2} \mathrm{O}_{2}$ is very small under visible light, only reaching up to $5 \%$. About $60 \%$ 2,4-DCP is degraded, mainly attributed to the production of electron-hole pairs by MIL-53(Fe) after the addition of $\mathrm{H}_{2} \mathrm{O}_{2}$ during the irradiation. It manifests that the synthesized MIL-53(Fe) catalyst has the limited degradation property. And the photocatalytic degradation efficiency of $\mathrm{BiOCl}$ can be roughly reached up to $30 \%$ under visible light after the addition of $10 \mathrm{uL} \mathrm{H}_{2} \mathrm{O}_{2}$. Surprisingly, photocatalytic degradation efficiency of MIL-53(Fe)/BiOCl-10 can be reached up to nearly $100 \%$ under visible light after the addition of $10 \mathrm{uL} \mathrm{H}_{2} \mathrm{O}_{2}$ within 150 min. Fig.4(b) shows degradation rate constant $\mathrm{k}$ of photo-Fenton. As is exhibited from the histogram, photocatalytic degradation rate constant $\mathrm{k}$ of the MI-53(Fe)/visible light $/ \mathrm{H}_{2} \mathrm{O}_{2}, \mathrm{BiOCl} /$ visible light $/ \mathrm{H}_{2} \mathrm{O}_{2}$, blank/visible light $/ \mathrm{H}_{2} \mathrm{O}_{2}, 10 \% /$ visible light $/ \mathrm{H}_{2} \mathrm{O}_{2}$, blank/visible light and $10 \% / \mathrm{H}_{2} \mathrm{O}_{2}$ are that $0.00282 \mathrm{~min}^{-1}, 0.00109 \mathrm{~min}^{-1}, 0.0004883 \mathrm{~min}^{-1}, 0.01112 \mathrm{~min}^{-1}$, $0.000280 \mathrm{~min}^{-1}$ and $0.000431 \mathrm{~min}^{-1}$. 

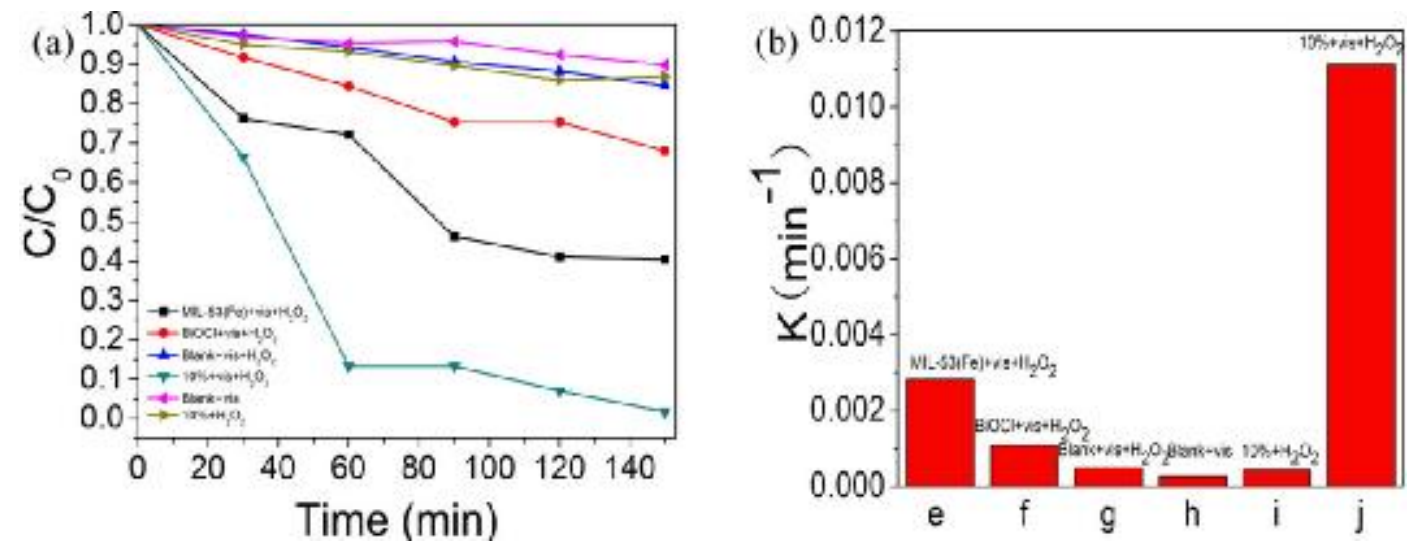

Fig.4(a) the degradation activity of 2,4-DCP over MIL-53(Fe)/BiOCl-10 composites in 150 min.(Reaction:50 mg catalyst, $50 \mathrm{~mL} 20 \mathrm{mg} / \mathrm{L} 2,4-\mathrm{DCP}, 10 \mathrm{uLH}_{2} \mathrm{O}_{2}$ ) and (b) pseudo-first-order rate constant $\mathrm{k}$ of system under visible light irradiation.

Fig.5 shows effect of the volume of $\mathrm{H}_{2} \mathrm{O}_{2}$ and effect of initial $\mathrm{pH}$ on the degradation of 2,4-DCP over MIL-53(Fe)/BiOCl-10/visible light/ $\mathrm{H}_{2} \mathrm{O}_{2}$ system. Fig.5(a) shows the degradation picture of 2,4-DCP is surveyed by varying the volume of $\mathrm{H}_{2} \mathrm{O}_{2}$ under a given environment. When the volume of $\mathrm{H}_{2} \mathrm{O}_{2}$ is added from $5 \mathrm{uL}$ to $50 \mathrm{uL}$, the degradation efficiency is increased from $65 \%$ to $99 \%$. The increasing degradation rate is attributed to the increasement of $\bullet \mathrm{OH}$ with increasing the the volume of $\mathrm{H}_{2} \mathrm{O}_{2}$. However, when the volume of $\mathrm{H}_{2} \mathrm{O}_{2}$ is from $20 \mathrm{uL}$ to $50 \mathrm{uL}$, the degradation efficiency is increasing slightly. It can be clarified that extra $\mathrm{H}_{2} \mathrm{O}_{2}$ molecules are acted as the scavenger of $\cdot \mathrm{OH}$ to produce perhydroxy radicals owning lower oxidation potential ${ }^{[30]}$. As is shown in Fig.5(b), the $\mathrm{pH}$ of the solution which is adjusted by $\mathrm{HCl}$ or $\mathrm{NaOH}$ can influence the degradation effect of 2,4-DCP. The original $\mathrm{pH}$ of the system is 6. Obviously, while the $\mathrm{pH}$ of the solution is increased from 3 to 10, the photocatalytic activity of the composites is gradually decreasing. Nevertheless, when the $\mathrm{pH}$ is 2 , the photocatalytic degradation can only reach up to $50 \%$. It is ascribed to formation of oxoniumion $\left(\mathrm{H}_{3} \mathrm{O}_{2}{ }^{+}\right)$. And it could strengthen the stability of $\mathrm{H}_{2} \mathrm{O}_{2}$ preventing the production of $\bullet \mathrm{OH}$ radicals, furthermore, iron ion could be leached to the solution from the composite materials while $\mathrm{pH}$ is inferior than $3^{[31]}$.
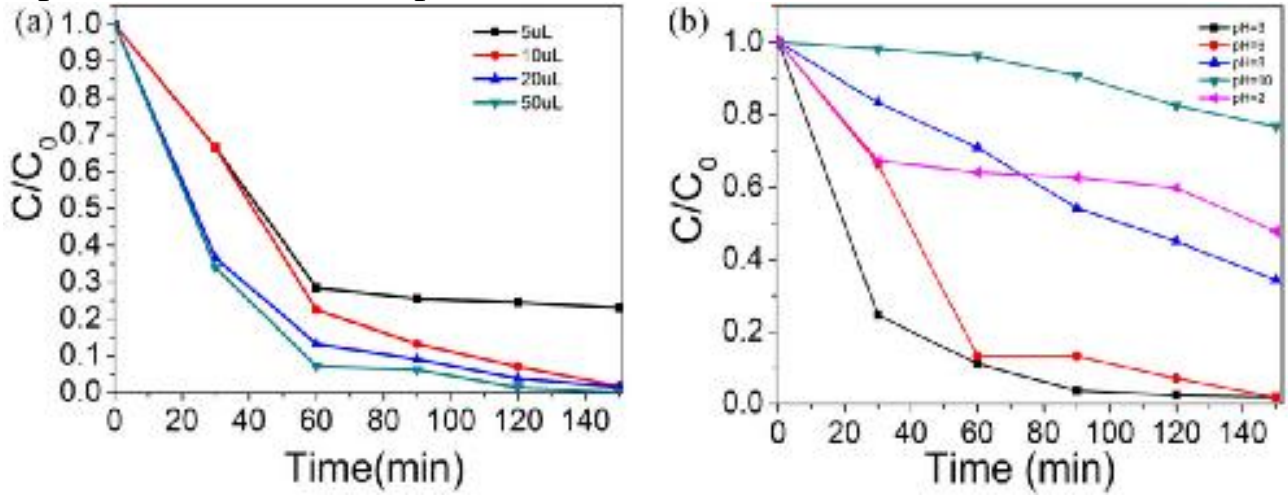

Fig.5(a) Effect of the volume of $\mathrm{H}_{2} \mathrm{O}_{2}$ on the degradation of 2,4-DCP over MIL-53(Fe)/BiOCl-10/visible light $/ \mathrm{H}_{2} \mathrm{O}_{2}$ system. Experimental conditions: 2,4-DCP, $20 \mathrm{mgL}^{-1}$; MIL-53(Fe)/BiOCl-10, $1 \mathrm{gL}^{-1}$; and initial $\mathrm{pH}$. (b) Effect of initial $\mathrm{pH}$ on the degradation of 2,4-DCP. Experimental conditions: 2,4-DCP, 20mg L ${ }^{-1} ; \mathrm{H}_{2} \mathrm{O}_{2}, 10 \mathrm{uL}$ and MIL-53(Fe)/BiOCl-10, 1 $\mathrm{gL}^{-1}$.

\section{Mechanism for photo-Fenton system}

The optical characterization have tested the visible-light responsiveness of the composite material. To verify this assumption, the measurement of photocurrent over MIL-53( $\mathrm{Fe}), \mathrm{BiOCl}$ and MIL-53(Fe)/BiOCl-10 is carried out. It is clarified in Fig.6(a) that a sudden and stable photocurrent response is tested for light-on and light-off during the samples of $\mathrm{MIL}-53(\mathrm{Fe}), \mathrm{BiOCl}$ and MIL-53(Fe)/BiOCl-10. As is given in Fig.6(a), MIL-53(Fe) shows a very low photocurrent density. 
The primordial $\mathrm{BiOCl}$ has a bit higher photocurrent than $\mathrm{MIL}-53(\mathrm{Fe})$ during the $\mathrm{PC}$ test. However, the MIL-53(Fe)/BiOCl-10 implies the distinguished enhancement of photocurrent density than MIL-53(Fe) and $\mathrm{BiOCl}$, which verifies the efficient charge transfer between MIL-53(Fe) and BiOCl and provides more survival time of electrons. For the sake of further studying the contact interface charge transport performance of MIL-53(Fe), BiOCl and MIL-53(Fe)/BiOCl-10 composites, the EIS measurements are tested. As is given in Fig.6(b), the radius of the impedance indicates the reaction speed happening on the surface of the electrode. The MIL-53(Fe)/BiOCl-10 has the smaller radius of the impedance than $\mathrm{MIL}-53(\mathrm{Fe})$ and $\mathrm{BiOCl}$ demonstrating a rapid contact interfacial transfer. It could also prove valid separation efficiency of electron-hole pairs occurring in the materials. The results are coincident well with the photocurrent test and photoluminescence spectra test. So the photocurrent spectra, photoluminescence spectra test and EIS Nyquist plots prove the rapid separation efficiency of electron-hole pairs in the $\mathrm{MIL}-53(\mathrm{Fe}) / \mathrm{BiOCl}$ composites, which is promising for the intensive photo-Fenton activity.
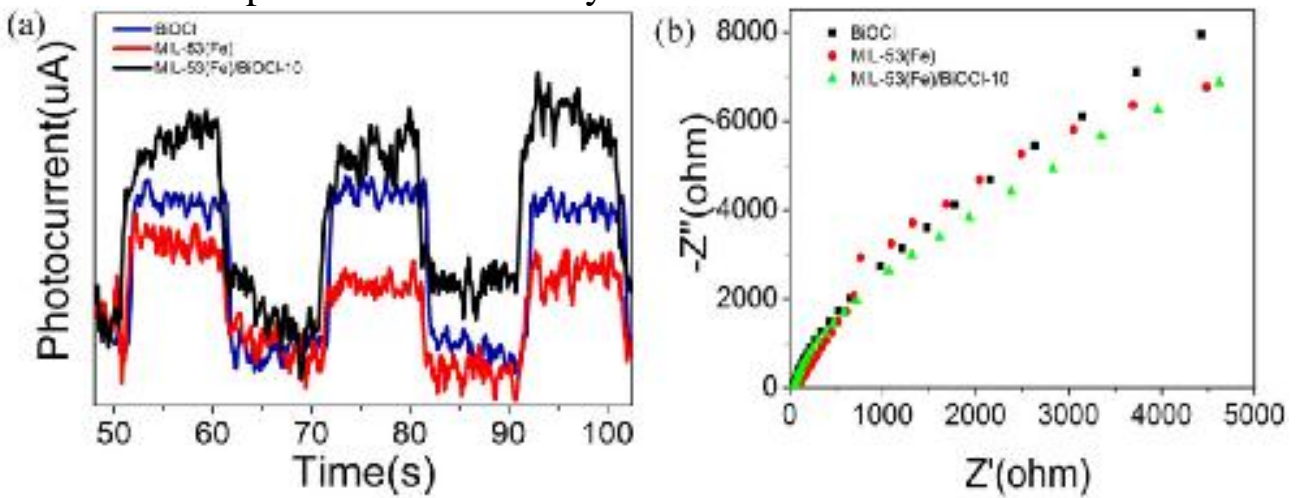

Fig.6(a)Transient photocurrent response of MIL-53(Fe), BiOCl and MIL-53(Fe)/BiOCl-10 in 0.1M PBS aqueous solution under intermittent visible light. (b) EIS Nyquist plots of the BiOCl, MIL-53(Fe) and MIL-53(Fe)/BiOCl-10 under dark condition.

Obviously, the electron shift in MIL-53(Fe)/BiOCl-10 could be improved immensely by the rapid separation efficiency of photoelectron-hole pairs. Therefore, the MIL-53(Fe)/BiOCl-10 also shows more excellent photoelectochemical performance than $\mathrm{BiOCl}$. Based on our study, a possible oxidation mechanism is detailedly illuminated. The electron is transferred from the valence band of MIL-53(Fe) to the conduction band of it under visible light. The electron would be combined with $\mathrm{Fe}^{3+}$ to produce $\mathrm{Fe}^{2+}$. The generated $\mathrm{Fe}^{2+}$ is actived by $\mathrm{H}_{2} \mathrm{O}_{2}$ in an acidic environment producing - $\mathrm{OH}$. At the same time, $\mathrm{Fe}^{2+}$ is also reduced by $\mathrm{H}_{2} \mathrm{O}_{2}$ generating $\mathrm{Fe}^{3+}$. Due to the rapid separation efficiency of charge about composite material, it would generate more electron and accelerate the prouduction rate of $\bullet \mathrm{OH}$. A series of reaction process makes the higher photo-Fenton degradation effect.

\section{Conclusions}

In this work, an original MIL-53(Fe)/BiOCl-10 composites has been man-made by a simple two-step solvothermal method, which displays excellent performance and good stability on account of excellent photo-Fenton degradation activity under visible light. At the same time, the marked improvement of photo-Fenton performance could be due to the synergistic effect of the MIL-53(Fe) and $\mathrm{BiOCl} .20 \mathrm{mg} / \mathrm{L} 2,4-\mathrm{DCP}$ has been degraded completely by adding $10 \mathrm{uL} 30 \% \mathrm{H}_{2} \mathrm{O}_{2}$ after 150 min. In the meanwhile, the test of photo-Fenton degradation of $\mathrm{H}_{2} \mathrm{O}_{2}$ dosage and $\mathrm{pH}$ value prove that the MIL-53(Fe)/BiOCl photocatalyst could be put into use in the broad environment. The photo-Fenton mechanism analysis for the performance reinforcement of the MIL-53(Fe)/BiOCl-10 has been proposed by illuminating the rapid separation efficiency of electron-hole pairs. This paper results may provide a bright prospects for the photocatalytic degradation of stable pollutants in practical applications. 


\section{Acknowledgements}

This work was nancially supported by the National Natural Science Foundation of China (no. 21271027, 21103069, and 40672158), the 863 Project of China (no. 20140AA065103-1), Scientic Research Reward Fund for Excellent Young and Middle-AgeScientists of Shandong Province (BS2012HZ001), and Scientific Research Foundation for Doctors of University of of Jinan (XBS1037, XKY1321, and XKY1043).

\section{References}

[1] F. Ye, H. Li, H. Yu, S. Chen, X. Quan, Constructing BiVO $4-A u @ C d S$ photocatalyst with energic charge-carrier separation capacity derived from facet induction and Z-scheme bridge for degradation of organic pollutants, Appl. Catal. B-Environ., 227 (2018) 258-265.

[2] M. Shakeel, B. Li, M. Arif, G. Yasin, W. Rehman, A.U. Khan, S. Khan, A. Khan, J. Ali, Controlled Synthesis of highly proficient and durable hollow hierarchical heterostructured (Ag-AgBr/HHST): A UV and Visible light active photocatalyst in degradation of organic pollutants, Appl. Catal. B-Environ., 227 (2018) 433-445.

[3] K. Park, I. Ali, J.-O. Kim, Photodegradation of perfluorooctanoic acid by graphene oxide-deposited $\mathrm{TiO}_{2}$ nanotube arrays in aqueous phase, Journal of environmental management, 218 (2018) 333-339.

[4] D. Maucec, A. Suligoj, A. Ristic, G. Drazic, A. Pintar, N.N. Tusar, Titania versus zinc oxide nanoparticles on mesoporous silica supports as photocatalysts for removal of dyes from wastewater at neutral pH, Catalysis Today, 310 (2018) 32-41.

[5] B. Rezaei, N. Irannejad, A.A. Ensafi, 3D $\mathrm{TiO}_{2}$ self-acting system based on dye-sensitized solar cell and $\mathrm{g}_{-} \mathrm{C}_{3} \mathrm{~N}_{4} / \mathrm{TiO}_{2}$-MIP to enhanced photodegradation performance, Renewable Energy, 123 (2018) 281-293.

[6] C. Zhang, X. Li, S. Zheng, Y. Ma, C. Hu, C. Li, S. Duo, Q. Hu, Construction of $\mathrm{TiO}_{2}$ nanobelts- $\mathrm{Bi}_{2} \mathrm{O}_{4}$ heterojunction with enhanced visible light photocatalytic activity, Colloids and Surfaces a-Physicochemical and Engineering Aspects, 548 (2018) 150-157.

[7] Y. Wang, Q. Wu, Y. Li, L. Liu, Z. Geng, Y. Li, J. Chen, W. Bai, G. Jiang, Z. Zhao, Controlled fabrication of $\mathrm{TiO}_{2} / \mathrm{C}_{3} \mathrm{~N}_{4}$ core-shell nanowire arrays: a visible-light-responsive and environmental-friendly electrode for photoelectrocatalytic degradation of bisphenol A, Journal of Materials Science, 53 (2018) 11015-11026.

[8] B.-K. Choi, W.-K. Choi, S.-J. Park, M.-K. Seo, One-Pot Synthesis of Ag- $\mathrm{TiO}_{2} / \mathrm{Nitrogen}^{-D o p e d}$ Graphene Oxide Nanocomposites and Its Photocatalytic Degradation of Methylene Blue, Journal of Nanoscience and Nanotechnology, 18 (2018) 6075-6080.

[9] F.J. Guo, J. Jia, D.M. Dai, H.T. Gao, The electronic properties and enhanced photocatalytic mechanism of $\mathrm{TiO}_{2}$ hybridized with $\mathrm{MoS}_{2}$ sheet, Physica E, 97 (2018) 31-37.

[10] M.T. Qamar, M. Aslam, Z.A. Rehan, M.T. Soomro, J.M. Basahi, I.M.I. Ismail, T. Almeelbi, A. Hameed, The influence of p-type $\mathrm{Mn}_{3} \mathrm{O}_{4}$ nanostructures on the photocatalytic activity of $\mathrm{ZnO}$ for the removal of bromo and chlorophenol in natural sunlight exposure, Appl. Catal. B-Environ., 201 (2017) 105-118.

[11] J. Li, D. Luo, C. Yang, S. He, S. Chen, J. Lin, L. Zhu, X. Li, Copper(II) imidazolate frameworks as highly efficient photocatalysts for reduction of $\mathrm{CO}_{2}$ into methanol under visible light irradiation, Journal of Solid State Chemistry, 203 (2013) 154-159.

[12] R.M. Abdelhameed, M.M.Q. Simoes, A.M.S. Silva, J. Rocha, Enhanced Photocatalytic Activity of MIL-125 by Post-Synthetic Modification with Cr-III and Ag Nanoparticles, Chemistry-a European Journal, 21 (2015) 11072-11081.

[13] M.Y. Masoomi, M. Bagheri, A. Morsali, High efficiency of mechanosynthesized Zn-based metal-organic frameworks in photodegradation of congo red under UV and visible light, Rsc Advances, 6 (2016) 13272-13277. 
[14] H. Wang, X. Yuan, Y. Wu, G. Zeng, X. Chen, L. Leng, H. Li, Synthesis and applications of novel graphitic carbon nitride/metal-organic frameworks mesoporous photocatalyst for dyes removal, Appl. Catal. B-Environ., 174 (2015) 445-454.

[15] Q. Liu, C. Zeng, L. Ai, Z. Hao, J. Jiang, Boosting visible light photoreactivity of photoactive metal-organic framework: Designed plasmonic Z-scheme Ag/AgCl@MIL-53-Fe, Appl. Catal. B-Environ., 224 (2018) 38-45.

[16] R. Liang, F. Jing, L. Shen, N. Qin, L. Wu, MIL-53(Fe) as a highly efficient bifunctional photocatalyst for the simultaneous reduction of $\mathrm{Cr}(\mathrm{VI})$ and oxidation of dyes, Journal of Hazardous Materials, 287 (2015) 364-372.

[17] W. Huang, N. Liu, X. Zhang, M. Wu, L. Tang, Metal organic framework g- $\mathrm{C}_{3} \mathrm{~N}_{4} / \mathrm{MIL}-53(\mathrm{Fe})$ heterojunctions with enhanced photocatalytic activity for $\mathrm{Cr}(\mathrm{VI})$ reduction under visible light, Applied Surface Science, 425 (2017) 107-116.

[18] L. Hu, G. Deng, W. Lu, S. Pang, X. Hu, Deposition of CdS nanoparticles on MIL-53(Fe) metal-organic framework with enhanced photocatalytic degradation of RhB under visible light irradiation, Applied Surface Science, 410 (2017) 401-413.

[19] B. Sarwan, B. Pare, A.D. Acharya, The effect of oxygen vacancies on the photocatalytic activity of $\mathrm{BiOCl}$ nanocrystals prepared by hydrolysis and UV light irradiation, Materials Science in Semiconductor Processing, 25 (2014) 89-97.

[20] B. Pare, B. Sarwan, S.B. Jonnalagadda, Photocatalytic mineralization study of malachite green on the surface of $\mathrm{Mn}$-doped $\mathrm{BiOCl}$ activated by visible light under ambient condition, Applied Surface Science, 258 (2011) 247-253.

[21] Y. Chen, J. Fang, S. Lu, Y. Wu, D. Chen, L. Huang, C. Cheng, L. Ren, X. Zhu, Z. Fang, Plasmonic Ag-pillared rectorite as catalyst for degradation of 2,4-DCP in the $\mathrm{H}_{2} \mathrm{O}_{2}$-containing system under visible light irradiation, Journal of Hazardous Materials, 297 (2015) 278-285.

[22] Z. Yang, X. Xu, X. Liang, C. Lei, Y. Wei, P. He, B. Lv, H. Ma, Z. Lei, MIL-53(Fe)-graphene nanocomposites: Efficient visible-light photocatalysts for the selective oxidation of alcohols, Applied Catalysis B: Environmental, 198 (2016) 112-123.

[23] S. Fang, C. Ding, Q. Liang, Z. Li, S. Xu, Y. Peng, D. Lu, In-situ precipitation synthesis of novel $\mathrm{BiOCl} / \mathrm{Ag}_{2} \mathrm{CO}_{3}$ hybrids with highly efficient visible-light-driven photocatalytic activity, Journal of Alloys and Compounds, 684 (2016) 230-236.

[24] D. Wang, R. Huang, W. Liu, D. Sun, Z. Li, Fe-Based MOFs for Photocatalytic $\mathrm{CO}_{2}$ Reduction: Role of Coordination Unsaturated Sites and Dual Excitation Pathways, Acs Catalysis, 4 (2014) 4254-4260.

[25] J. Yang, X. Niu, S. An, W. Chen, J. Wang, W. Liu, Facile synthesis of $\mathrm{Bi}_{2} \mathrm{MoO}_{6}-\mathrm{MIL}-100(\mathrm{Fe})$ metal-organic framework composites with enhanced photocatalytic performance, Rsc Advances, 7 (2017) 2943-2952.

[26] R. Liang, L. Shen, F. Jing, N. Qin, L. Wu, Preparation of MIL-53(Fe)-Reduced Graphene Oxide Nanocomposites by a Simple Self-Assembly Strategy for Increasing Interfacial Contact: Efficient Visible-Light Photocatalysts, ACS Applied Materials \& Interfaces, 7 (2015) 9507-9515.

[27] V. Gia-Thanh, P. Minh-Hao, D. Trong-On, Direct synthesis and mechanism of the formation of mixed metal $\mathrm{Fe}_{2} \mathrm{Ni}-\mathrm{MIL}-88 \mathrm{~B}$, Crystengcomm, 15 (2013) 9694-9703.

[28] G.-T. Vuong, M.-H. Pham, T.-O. Do, Synthesis and engineering porosity of a mixed metal $\mathrm{Fe}_{2} \mathrm{Ni}$ MIL-88B metal-organic framework, Dalton Transactions, 42 (2013) 550-557.

[29] W. Yue, S.-L. Suraru, D. Bialas, M. Mueller, F. Wuerthner, Synthesis and Properties of a New Class of Fully Conjugated Azahexacene Analogues, Angewandte Chemie-International Edition, 53 (2014) 6159-6162.

[30] L. Ai, C. Zhang, L. Li, J. Jiang, Iron terephthalate metal-organic framework: Revealing the effective activation of hydrogen peroxide for the degradation of organic dye under visible light irradiation, Appl. Catal. B-Environ., 148 (2014) 191-200. 
[31] L. Ren, S.Y. Lu, J.Z. Fang, Y. Wu, D.Z. Chen, L.Y. Huang, Y.F. Chen, C. Cheng, Y. Liang, Z.Q. Fang, Enhanced degradation of organic pollutants using $\mathrm{Bi}_{25} \mathrm{FeO}_{40}$ microcrystals as an efficient reusable heterogeneous photo-Fenton like catalyst, Catalysis Today, 281 (2017) 656-661. 